\title{
The effect of Cu-doping on the magnetic and transport properties of $\mathrm{La}_{0.7} \mathrm{Sr}_{0.3} \mathrm{MnO}_{3}$
}

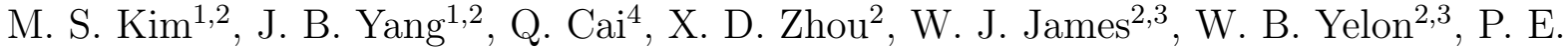 \\ Parris $^{1}$, D. Buddhikot ${ }^{5}$, S. K. Malik ${ }^{5}$ \\ ${ }^{1}$ Department of Physics, University of Missouri-Rolla, Rolla, MO 65409 \\ ${ }^{2}$ Graduate Center for Materials Research, University of Missouri-Rolla, Rolla, MO 65409 \\ ${ }^{3}$ Department of Chemistry, University of Missouri-Rolla, Rolla, MO 65409 \\ ${ }^{4}$ Department of Physics, University of Missouri-Columbia, Columbia, MO 65211 \\ ${ }^{5}$ Tata Institute of Fundamental Research, Colaba, Mumbai 400-005, India
}

\begin{abstract}
The effects of $\mathrm{Cu}$-doping on the structural, magnetic, and transport properties of $\mathrm{La}_{0.7} \mathrm{Sr}_{0.3} \mathrm{Mn}_{1-x} \mathrm{Cu}_{x} \mathrm{O}_{3}(0 \leq \mathrm{x} \leq 0.20)$ have been studied using neutron diffraction, magnetization and magnetoresistance(MR) measurements. All samples show the rhombohedral structure with the $R \overline{3} c$ space-group from 10K to room temperature(RT). Neutron diffraction data suggest that some of the $\mathrm{Cu}$ ions have a $\mathrm{Cu}^{3+}$ state in these compounds. The substitution of $\mathrm{Mn}$ by $\mathrm{Cu}$ affects the $\mathrm{Mn}-\mathrm{O}$ bond length and $\mathrm{Mn}-\mathrm{O}-\mathrm{Mn}$ bond angle resulting from the minimization of the distortion of the $\mathrm{MnO}_{6}$ octahedron. Resistivity measurements show that a metal to insulator transition occurs for the $\mathrm{x} \geq$ 0.15 samples. The $\mathrm{x}=0.15$ sample shows the highest $\mathrm{MR}(\approx 80 \%)$, which might result from the co-existence of $\mathrm{Cu}^{3+} / \mathrm{Cu}^{2+}$ and the dilution effect of $\mathrm{Cu}$-doping on the double exchange interaction.
\end{abstract}

PACS numbers: $75.50 \mathrm{Ee}, 61.10 \mathrm{Nz}, 76.80+\mathrm{y}, 81.40-\mathrm{Z}$ 


\section{INTRODUCTION}

The $\mathrm{ABO}_{3}(\mathrm{~A}=$ trivalent rare earth atom, $\mathrm{B}=$ divalent alkaline metal $)$ perovskites have attracted considerable attention because of the anomalous magnetic and transport properties such as colossal magnetoresistance(CMR), metal-insulator transitions(MIT). [1-3] The $\mathrm{La}_{1-x} \mathrm{Sr}_{x} \mathrm{MnO}_{3}$ pervoskites are a canonical $\mathrm{ABO}_{3}$-type, CMR material. It has been reported that double-exchange(DE) interactions together with Jahn-Teller(JT) distortions in the $\mathrm{MnO}_{6}$ octahedron may be required to account for the large MR effects. [4-7] Because the $\mathrm{Mn}$ ion is the center of the DE interaction, the role of the Mn atom and its local environment have become the focus of much of the research on manganese perovskites. To investigate the CMR associated with the lattice deformation and charge ordering of the crucial Mn-O-Mn network, many early studies were carried out by doping the A-site with divalent atoms $(\mathrm{Ca}, \mathrm{Sr}, \mathrm{Ba}$, etc). [8-10] Recently, it has also been shown that substitution

of $\mathrm{Mn}(\mathrm{B}$-site) by other atoms dramatically affects the magnetic and transport properties of manganese perovskites. [11-14] The B site modification directly affects the Mn network by changing the $\mathrm{Mn}^{3+} / \mathrm{Mn}^{4+}$ ratio and the electron carrier density, which may provide a better understanding of the mechanism for CMR effects in the perovskites.

In this study, we report the effects of replacing $\mathrm{Mn}$ with $\mathrm{Cu}$ on the structural, magnetic and transport properties of $\mathrm{La}_{0.7} \mathrm{Sr}_{0.3} \mathrm{Mn}_{1-x} \mathrm{Cu}_{x} \mathrm{O}_{3}$ with $0 \leq \mathrm{x} \leq 0.20$.

\section{EXPERIMENTAL}

Samples of $\mathrm{Cu}$-substituted $\mathrm{La}_{0.7} \mathrm{Sr}_{0.3} \mathrm{Mn}_{1-x} \mathrm{Cu}_{x} \mathrm{O}_{3}$, with $0 \leq \mathrm{x} \leq 0.20$, were prepared using the conventional solid state reaction method. Highly purified $\mathrm{La}_{2} \mathrm{O}_{3}, \mathrm{SrCO}_{3}, \mathrm{CuO}$, $\mathrm{MnO}$ were mixed in stoichiometric ratios, ground, and then pelletized under 3,000 psi pressure to a $1 \mathrm{~cm}$ diameter. The pelletized samples were fired at $1350^{\circ} \mathrm{C}$ in air for $41 / 2$ hours, then reground and sintered at $1100^{\circ} \mathrm{C}$ for 24 hours. Sintered samples were cooled to $900^{\circ} \mathrm{C}$ in the oven and removed from the furnace, then finally cooled to RT in air. X-ray 
diffraction of the powders was carried out at RT using a SCINTAG diffractometer with Cu$\mathrm{K} \alpha$ radiation. Powder neutron diffraction experiments were performed at the University of Missouri-Columbia Research Reactor(MURR) using neutrons of wavelength $\lambda=1.4875 \AA$. Refinement of the neutron diffraction data was carried out using the FULLPROF program. [18] Magnetic measurements were conducted with a SQUID magnetometer and resistivity data were obtained using a physical properties measurement system(PPMS) with a standard four-point probe method.

\section{RESULTS AND DISCUSSION}

X-ray diffraction studies of $\mathrm{La}_{0.7} \mathrm{Sr}_{0.3} \mathrm{Mn}_{1-x} \mathrm{Cu}_{x} \mathrm{O}_{3}$ samples with $0 \leq \mathrm{x} \leq 0.20$ indicate that all samples are single phase and all peak positions can be indexed to $\mathrm{La}_{0.67} \mathrm{Sr}_{0.33} \mathrm{MnO}_{2.91}(\mathrm{JCPDS} 50-0308)$. To further investigate the structure distortion and magnetic properties of these compounds, powder neutron diffraction data were collected at RT and 10K. The typical neutron diffraction patterns of $\mathrm{La}_{0.7} \mathrm{Sr}_{0.3} \mathrm{Mn}_{0.9} \mathrm{Cu}_{0.1} \mathrm{O}_{3}$ measured at $10 \mathrm{~K}$ and RT are shown in Fig. 1. All patterns can be fitted well with the $R \overline{3} \mathrm{c}$ rhombohedral space-group (No.167). Refined lattice parameters and magnetic moments for the compounds are listed in Table I. At RT, the lattice parameters $a, c$ and the unit cell volumes decrease with increasing $\mathrm{Cu}$ content. At 10K, the lattice parameters and unit cell volume remain nearly constant with increasing $\mathrm{Cu}$ content. The refined magnetic moments of $\mathrm{Mn}$ atoms at $10 \mathrm{~K}$ and $\mathrm{RT}$ decrease with increasing $\mathrm{Cu}$ content. These results agree well with the values obtained from magnetic measurements.

Generally, the B-site doping will directly change the $\mathrm{Mn}^{3+} / \mathrm{Mn}^{4+}$ ratio and the exchange interaction of Mn-Mn. The lattice parameters and crystal structure will be affected due to the mismatch of the ionic radius between the Mn ions and the doping ions. Even though the most stable state of $\mathrm{Cu}$ is $\mathrm{Cu}^{2+}$, the $\mathrm{Cu}^{2+}(6$ coordination $)$ radius is about $0.73 \AA$, which is

much larger than the radius of $\mathrm{Mn}^{3+}(0.645 \AA)$ and $\mathrm{Mn}^{4+}(0.53 \AA)$. [15] The substitution of $\mathrm{Mn}$ by $\mathrm{Cu}^{2+}$ will lead to an expansion of the unit cell rather than a contraction. Therefore, 
the decrease of the unit cell volume with $\mathrm{Cu}$-doping at $\mathrm{RT}$ suggests that some of the $\mathrm{Cu}$ ions are in a $\mathrm{Cu}^{3+}$ state with a radius of $0.54 \AA$, which is smaller than that of $\mathrm{Mn}^{3+}$ and larger than that of $\mathrm{Mn}^{4+}$. Furthermore, this is able to account for the valence states of $\mathrm{Mn}$ in order to satisfy the charge balance in these compounds. It should be pointed out that both $\mathrm{Cu}^{2+}$ and $\mathrm{Cu}^{3+}$ states may appear in these compounds, which might be the reason that the changes of the unit cell volume and the lattice parameters are not linear with $\mathrm{Cu}$ content. A similar phenomenon has been observed in ( $\mathrm{La}, \mathrm{Ba}) \mathrm{Cu}_{1-x} \mathrm{Mn}_{x} \mathrm{O}_{3}$ compounds, where $\mathrm{Cu}^{3+}$ enters Mn sites. [14]

The average $(\mathrm{Mn}, \mathrm{Cu})-\mathrm{O}$ bond length and $(\mathrm{Mn}, \mathrm{Cu})-\mathrm{O}-(\mathrm{Mn}, \mathrm{Cu})$ bond angle extracted from the Rietveld refinements are shown in Fig. 2. At RT, the average bond length decreases gradually while the average bond angle increases up to $\mathrm{x}=0.10$ then slightly decreases for $x \geq 0.15$. At $10 \mathrm{~K}$, the average bond length decreases up to $\mathrm{x}=0.1$ and remains constant for $\mathrm{x} \geq 0.15$, while the average bond angle increases and attains a maximum value at $\mathrm{x}$ $=0.10$. The average bond length and the average bond angle are directly related through the oxygen positions and content. The refinement results indicate that there is no oxygen deficiency within error limits. Therefore the unusual changes in the average $(\mathrm{Mn}, \mathrm{Cu})-\mathrm{O}$ bond length and $(\mathrm{Mn}, \mathrm{Cu})-\mathrm{O}-(\mathrm{Mn}, \mathrm{Cu})$ bond angle between $\mathrm{RT}$ and $10 \mathrm{~K}$ might be related to the magnetostriction that reflects the magnetic ordering temperature and the existence of mixed $\mathrm{Cu}^{2+} / \mathrm{Cu}^{3+}$ states. The internal strain in the $\mathrm{MnO}_{6}$ octahedron may be released by a small distortion of the $\mathrm{MnO}_{6}$ octahedra through changes in bond length and bond angle.

Fig. 3 shows the magnetization versus temperature (M-T) curves measured under field cooling (FC) and zero field cooling (ZFC) conditions in a magnetic field of 50 Oe for the $\mathrm{x}$ $=0.05,0.10$, and 0.15 samples. Two magnetic transition temperatures are shown for the samples with $\mathrm{x}=0.05$ and 0.10 . The neutron diffraction data do not show the presence of other phases in the $\mathrm{Cu}$-doped samples within the resolution of neutron diffraction analysis.

The electronic bandwidth $W$ has been used to explain the changes in the magnetic transition temperatures by varied A and B-site doping. [16] The empirical formula of the bandwidth $W$ for $\mathrm{ABO}_{3}$-type perovskites using the tight binding approximation [17] is $W \propto$ 
$\frac{\cos \omega}{\left(d_{M n-O}\right)^{3.5}}$, where $\omega=\frac{1}{2}\left(\pi-\theta_{\langle M n-O-M n\rangle}\right), d_{M n-O}$ is the average $(\mathrm{Mn}, \mathrm{Cu})-\mathrm{O}$ bond length, and $\theta_{\langle M n-O-M n\rangle}$ is the average $(\mathrm{Mn}, \mathrm{Cu})-\mathrm{O}-(\mathrm{Mn}, \mathrm{Cu})$ bond angle. The calculated relative bandwidth $W^{\prime}$ is listed in Table I. The bandwidth at RT is smaller than that at $10 \mathrm{~K}$ for a given $\mathrm{Cu}$ content. The change across the series is very small. At $\mathrm{RT}$, the increase in the bond angle and the decrease in bond length lead to an increase of the bandwidth which increases the overlap between the $\mathrm{O}-2 p$ and the Mn-3d orbitals. Therefore, the Cu-doping could enhance the exchange coupling of $\mathrm{Mn}^{3+}-\mathrm{Mn}^{4+}$, and increase the magnetic ordering temperature $\mathrm{T}_{C}$ at a low $\mathrm{Cu}$-doping ratio. This is consistent with the fact that the low Cu-doped samples $(x \leq 0.05)$ show almost no decrease in Curie temperature $\mathrm{T}_{C}$. At a high doping ratio, the magnetic dilution effect of $\mathrm{Cu}$ is predominant, which gives rise to a sharp drop in the Curie temperature for $x>0.10$.

Fig. 4 shows the temperature dependence of resistivity under various applied fields for $\mathrm{La}_{0.7} \mathrm{Sr}_{0.3} \mathrm{Mn}_{1-x} \mathrm{Cu}_{x} \mathrm{O}_{3}(x=0.10,0.15$, and 0.20). With increasing $\mathrm{Cu}$ content, the resistivity of the compound increases, while the resistivity decreases with increasing magnetic field. This is ascribed to a reduction of the $\mathrm{Mn}^{3+} / \mathrm{Mn}^{4+}$ ratio to account for the DE interaction and a reduction in the number of hopping electrons and hopping sites by $\mathrm{Cu}$ substitution. In addition, $\mathrm{Cu}^{3+}$ has 8 electrons in the $d$-orbital, and is highly localized with a strong Coulomb repulsion. Therefore, the $\mathrm{Mn}^{3+} e_{g \uparrow}^{1}$ electron may not itinerate through the $\mathrm{Mn}^{3+}$ $\mathrm{Cu}^{3+}$ chains but through the antiferromagnetic super-exchange chains of $\mathrm{Mn}^{3+}-\mathrm{Mn}^{3+}$ and $\mathrm{Mn}^{4+}-\mathrm{Mn}^{4+}$. Therefore $\mathrm{Cu}$ substitution weakens the DE interaction, disturbs the Mn-O-Mn network, and creates short range ordered ferromagnetic clusters. As more $\mathrm{Cu}$ is substituted, more inhomogeneous small clusters are formed, leading to a broadening of the magnetic phase transition peak. Consequently, Cu-doping enhances antiferromagnetic super-exchange interactions and weakens DE interactions which reduces electron hopping sites and increases electronic resistivity.

For the $x \leq 0.10$ samples, metallic behavior is shown with decreasing temperature and for the samples with $x \geq 0.15$, a metal-insulator transition (MIT) appears.(see Fig. 3) A resistivity peak corresponding to the magnetic transition is present. There is no clear 
field-induced shift of maximum resistivity for all samples. The suppression of the resistivity by the applied magnetic field occurs over the entire temperature range for all samples. In the DE mechanism, the mobility of the charge carrier $e_{g}$ electrons improves if the localized spins are polarized. The applied field aligns the canted electron spins which should reduce the scattering of itinerant electrons with spins and thus the resistivity is reduced. The temperature dependence of the magnetoresistance was calculated with $\left[\mathrm{MR}=\left(\rho_{0}-\rho_{H}\right) / \rho_{0} \times\right.$ 100] under $\mathrm{H}=1,3$ and $5 \mathrm{~T}$. The $\mathrm{MR}$ increases with increasing $\mathrm{Cu}$ content up to $x \leq 0.15$ samples and shows the maximum $\mathrm{MR}=80 \%$ below $\mathrm{T}=100 \mathrm{~K}$, for the $x=0.15$ sample. The maximum MR decreases with further $\mathrm{Cu}$-doping. The bandwidth, $W$, which is associated with the small structure distortion cannot alone account for the CMR behavior of this system. The existence of $\mathrm{Cu}^{3+} / \mathrm{Cu}^{2+}$, the dilution effect of $\mathrm{Cu}$ on the DE interaction and the super-exchange interaction of Mn may be responsible for the MR behavior in these compounds.

In summary, we have investigated the structural, magnetic and electronic properties of $\mathrm{Cu}$-doped $\mathrm{La}_{0.7} \mathrm{Sr}_{0.3} \mathrm{Mn}_{1-x} \mathrm{Cu}_{x} \mathrm{O}_{3}$. All samples show the same crystal structure from $10 \mathrm{~K}$ to RT. The variations of the bond length and bond angle resulting from $\mathrm{Cu}$ substitution minimize the distortion of the $\mathrm{MnO}_{6}$ network and stabilize the rhombohedral structure. A mixture of $\mathrm{Cu}^{2+}$ and $\mathrm{Cu}^{3+}$ ions gives rise to a decrease of the unit cell volume and a change of the $\mathrm{Mn}$ valence states in these compounds. The metal to insulator transition for the samples with $\mathrm{x} \geq 0.15$ result from changes in the Mn-O-Mn interaction, bandwidth, Mn valence state and the charge carrier concentration in the $\mathrm{Cu}$-doped compounds.

\section{ACKNOWLEDGMENTS}

We thank Aranwela Hemantha for invaluable help with the magnetoresistance measurements. The support by DOE under DOE contract \#DE-FC26-99FT400054 is acknowledged. 


\section{REFERENCES}

[1] J. B. Goodenough, Magnetism and the Chemical Bond, Interscience, New-York/London (1963).

[2] A. Unishibara, Y. Moritomo, T. Arima, A. Asamitsu, G. Kido, and Y. Tokura, Phys. Rev. B 51, 14103 (1995).

[3] Y. Tomioka, A. Asamitsu, H. Kuwahara, Y. Tokura, Phys. Rev. B 53, R1689 (1996).

[4] C. Zener, Phys. Rev. 82, 403 (1951).

[5] P. W. Anderson, and H. Hasegawa, Phys. Rev. 100, 675 (1955).

[6] K. Kubo, N. Ohata, J. Phys. Soc. Japan 33, 21 (1972).

[7] A. J. Millis, P. B. Littlewood, and B. I. Shraiman, Phys. Rev. Lett. 74, 5144 (1995).

[8] J. J. Neumeier, K. Andres, and K. J. McClenllan, Phys. Rev. B, 59, 1701 (1999).

[9] M. Medarde, J. Mesot, P. Lacorre, S. Rosenkranz, P. Fischer, and K. Gobrecht, Phys. Rev. B 52, 9248 (1995).

[10] D. Cao, F. Bridges, M. Anderson, A. P. Ramirez, M. Olapinski, M. A. Subramanian, C. H. Booath, and G. H. Kwei, Phys. Rev. B. 64, 184409 (2001).

[11] C. Martin, A. Maignan, and B. Raveau, J. Mater. Chem. 6, 1245 (1996).

[12] J. Blasco, J. Garcia, J. M. De Teresa, M. R. Ibarra, J. Perez, P. A. Algarabel, and C. Marquina, Phys. Rev. B. 55, 8905 (1997).

[13] K. H. Ahn, X. W. Wu, K. Liu, and C. L. Chien, J. Appl. Phys. 81, 5505 (1997)

[14] S.L. Yuan, Y. Jiang, G. Li, J.Q. Li, Y.P. Yang, MX.Y. Zhang, P. Tang, Z, Huang, Phys. Rev. B. 61, 3211 (2004).

[15] R. D. Shannon, Acta Crystallogr. Sect. A: Cryst. Phys., Diffr., Theor. Gen. Crystallogr. 32, 751 (1976).

[16] P. G. Radaelli, G. Iannone, M. Marezio, H. Y. Hwang, S-W. Cheong, J. D. Jorgensen, and D. N. Argyriou, Phys. Rev. B. 56, 8265 (1997)

[17] W. A. Harrison, The electronic structure and properties of solids, Freeman, San Francisco (1980).

[18] Rodriguez-Carvajal J., Program: FULLPROF, Version 3.5d. 


\section{TABLES}

Table I. Refined parameters for $\mathrm{La}_{0.7} \mathrm{Sr}_{0.3} \mathrm{Mn}_{1-x} \mathrm{Cu}_{x} \mathrm{O}_{3}, R \overline{3} c$ space-group, at room temperature and $\mathrm{T}=10 \mathrm{~K}$. Numbers in parentheses are statistical errors. $a$ and $c$ are the lattice parameters. $m$ is magnetic moment. $V$ is the unit cell volume. $\chi^{2}$ is $\left[\mathrm{R}_{w p} / \mathrm{R}_{e x p}\right]^{2}$ where $\mathrm{R}_{w p}$ is the residual error of the weighted profile. The magnetic moments of the $\mathrm{x} \geq 0.15$ samples at RT are not refined. Electronic bandwidth parameter $W^{\prime}=10^{*} \cos \omega /\left(d_{M n-O}\right)^{3.5}$ (arb. unit).

\begin{tabular}{|c|c|c|c|c|c|}
\hline Composition (x) & 0.00 & 0.05 & 0.10 & 0.15 & 0.20 \\
\hline \multicolumn{6}{|c|}{$\mathrm{T}=300 \mathrm{~K}$} \\
\hline$a(\AA)$ & $5.5038(2)$ & $5.5003(2)$ & $5.4987(2)$ & $5.4982(2)$ & $5.4941(2)$ \\
\hline$c(\stackrel{\circ}{A})$ & $13.3552(5)$ & $13.3387(4)$ & $13.3341(5)$ & $13.3304(6)$ & $13.3180(6)$ \\
\hline$V\left(\AA^{3}\right)$ & $350.351(18)$ & $349.473(17)$ & $349.153(18)$ & $348.990(22)$ & $348.152(24)$ \\
\hline$m\left(\mu_{B}\right)$ & $2.512(28)$ & $1.975(30)$ & $1.411(101)$ & - & - \\
\hline$\chi^{2}(\%)$ & 2.81 & 2.69 & 2.91 & 4.89 & 5.36 \\
\hline$W^{\prime}$ & 0.953 & 0.956 & 0.958 & 0.959 & 0.961 \\
\hline \multicolumn{6}{|c|}{$\mathrm{T}=10 \mathrm{~K}$} \\
\hline$a(\stackrel{\circ}{A})$ & $5.4812(1)$ & $5.4845(1)$ & $5.4823(1)$ & $5.4858(1)$ & $5.4855(2)$ \\
\hline$c(\stackrel{\AA}{A})$ & $13.2759(3)$ & $13.2797(4)$ & $13.2737(4)$ & $13.2718(4)$ & $13.2637(4)$ \\
\hline$V\left(\AA^{3}\right)$ & $345.415(13)$ & $345.931(16)$ & $345.504(17)$ & $345.897(17)$ & $345.642(17)$ \\
\hline$m\left(\mu_{B}\right)$ & $3.445(24)$ & $3.327(27)$ & 3.160 & $2.272(50)$ & $0.727(93)$ \\
\hline$\chi^{2}(\%)$ & 3.18 & 2.76 & 3.30 & 2.67 & 2.82 \\
\hline$W^{\prime}$ & 0.967 & 0.968 & 0.969 & 0.966 & 0.966 \\
\hline
\end{tabular}




\section{FIGURES}

FIG. 1. Neutron diffraction patterns of $\mathrm{La}_{0.7} \mathrm{Sr}_{0.3} \mathrm{Mn}_{1-x} \mathrm{Cu}_{x} \mathrm{O}_{3}(\mathrm{x}=0.10)$ at room temperature and $10 \mathrm{~K}$.(The bottom curves(Yobs-Ycal) are the difference between experimental data and refinement data. The vertical bars indicate the magnetic(bottom) and Bragg(top) peak positions). Arrows indicate magnetic diffraction peaks.

FIG. 2. Average $(\mathrm{Mn}, \mathrm{Cu})-\mathrm{O}$ bond lengths $d_{M n-O}(\mathrm{a}),(\mathrm{Mn}, \mathrm{Cu})-\mathrm{O}-(\mathrm{Mn}, \mathrm{Cu})$ bond angles $\theta_{\langle M n-O-M n\rangle}(\mathrm{b})$ of $\mathrm{La}_{0.7} \mathrm{Sr}_{0.3} \mathrm{Mn}_{1-x} \mathrm{Cu}_{x} \mathrm{O}_{3}(\mathrm{x}=0,0.05,0.10,0.15,0.20)$ at room temperature and at $10 \mathrm{~K}$.

FIG. 3. The magnetization versus temperature(M-T) curves of $\mathrm{La}_{0.7} \mathrm{Sr}_{0.3} \mathrm{Mn}_{1-x} \mathrm{Cu}_{x} \mathrm{O}_{3}$ $(\mathrm{x}=0.05,0.10,0.15)$ measured under field cooling (FC) and zero field cooling (ZFC) conditions in a magnetic field of 50 Oe.

FIG. 4. Electric resistivity $\rho$ versus temperature for $\mathrm{La}_{0.7} \mathrm{Sr}_{0.3} \mathrm{Mn}_{1-x} \mathrm{Cu}_{x} \mathrm{O}_{3}(\mathrm{x}=0.10$ (a), 0.15(b), $0.20(\mathrm{c}))$ in applied magnetic field $\mathrm{H}=0,1,3,5 \mathrm{~T}$. 